\title{
Oscillation modes of vibrating feeders with vibro-impact adaptive drive at the output of reflacted ore from chambers of wining blocks
}

\author{
Heorhii Shevchenko ${ }^{1, *}$, Oleksandr Sushchenko ${ }^{1}$, and Halyna Zozulia ${ }^{1}$ \\ ${ }^{1}$ Institute of Geotechnical Mechanics named by N. Poljakov of National Academy of Sciences of \\ Ukraine, 49005, Dnipro, Simferopolska Str., 2a, Ukraine
}

\begin{abstract}
The oscillation modes of vibrating feeders with vibro-impact adaptive drive are researched, which are intended for output and loading of reflacted ore from chambers of wining blocks at underground mining, or other bulk media from bunkers and so on, under complicated vibration conditions. The resonant polyfrequency oscillations of the impactor of the vibro-impact drive of feeders with such drive in vibro-impact modes are excited, which through one-side elastic elements are transmitted to the feeder tray, and in the pillar of the reflacted ore in the chamber above the tray. With increasing load from the ore on the tray there is an increase in the intensity of the impactor vibration of the feeder vibro-impact drive with accelerations in hundreds $\mathrm{m} / \mathrm{s}^{2}$. Such oscillations increase the depth of dissemination of vibrational effects in a pillar of reflacted ore above the tray, which increases the efficiency and productivity of vibration output. Depending on the feeders parameters in its oscillatory system, various modes of vibro-impact oscillations are excited. The task of choosing the mode of variation of the feeder is to choose such parameters, which would ensure efficient vibration output of the rock mass and reliability of its operation.
\end{abstract}

\section{Introduction}

At the underground mining of minerals for the output and loading of reflacted ore from the chambers of winings blocks through the outlets (hollows), vibrating feeders are used [1-9]. Such vibration feeders are subject to high requirements for the strength and reliability of the construction, since they operate in conditions of bulk, under heavy load from ore, and from explosions at the destruction of oversized pieces of the rock mass and the elimination of its freezes in the chamber, as well as significant shock loads from pieces falling on the feeder tray.

Typically, these feeders are single-mass over-resonance systems with oscillation excitations from debalanced vibrators driven by asynchronous electric motors. The essential disadvantage of such systems is to reduce the intensity of vibration excitation of the feeder tray with increasing load on it from the pillar of the reflacted rock mass in the chamber. When working under a blockage it is possible to significantly reduce or almost complete

\footnotetext{
*Corresponding author: gashevchenko@ua.fm
} 
stopping of excitation of the rock mass above the tray, which greatly complicates the repair of vibration output process $[5,6]$. Note that vibration actively influences the parameters of the reflacted ore flow zone due to the static equilibrium bonds destruction and the adhesion forces reduction, and the friction between the pieces of the bulk medium, which increases the output productivity. In spite of this, the depth and intensity of the reflacted rock mass excitation above the tray are important factors at vibration output. Therefore, the providing of intensive excitation of the reflacted ore in the chamber above the tray and the nonstopping of its excitation at the feeder operation under the blockage is actual. This allows to reduce the probability of occurrence of ore freezing in the chamber and to increase the vibration output.

Such requirements correspond to vibrating feeders with vibro-impact adaptive drive [1], which are double-mass dynamic systems, which are connected with each other by two-side and one-side elastic bonds, which are installed between the feeder tray and the vibro-impact drive impactor, on which the debalanced vibrator is fixed. In such a system, resonant polyfrequency oscillations of the impactor can be excited [4], which are transmitted to the feeder tray with the reflacted rock mass. With increasing loads from the pillar of the rock mass above the tray, due to the decrease in the amplitude of its oscillations, dynamic gaps between one-sided elastic elements installed on the tray and the the vibro-impact drive impactor are increased and which limit its moving. At the same time, the phases of the impactor and tray oscillations vary, which, with increasing load, gradually practically from in-phase become antiphase. The spectral density of the frequency spectrum of oscillations is also varied due to excitation the additional harmonics in the feeder vibrational system. There is a significant (at times) increase in the intensity of the oscillations of the vibroimpact drive impactor, which, accordingly, is transmitted to the tray and the rock mass on it. Thus, by changing the parameters and energy of the impactor oscillations, the vibroimpact drive adapts to the change in the load on the tray from the pillar of the rock mass in the wining block chamber.

It should be noted that polyfrequency oscillations contribute to the increase of the efficiency of the technological process of reflacted ore vibrations output from the wining blocks chambers, due to the increase in the intensity and depth of excitation of the rock mass in the chamber above the feeder tray and the speed of its displacement [1-3]. Therefore, the growth of the oscillations frequency spectrum spectral density positively affects the vibration output. In this case, an increase in the level and depth of vibration dissemination in the massive of reflacted ore, the static equilibrium bonds destruction and the adhesive forces and friction between the pieces of reflacted ore reduction is provided.

\section{Method}

Adjustment of vibrational oscillation parameters of vibrating feeders with a vibro-mpact adaptive drive must be ensured that in normal vibration output modes, stationary vibroimpact oscillations of the feeder are performed, at the nominal operating conditions of the asynchronous motor of vibration drive. As the load increases, acceleration of the impactor of the vibro-impact drive also increases, and when operating under a blockage, the parameters of its oscillations should be changed so that the acceleration does not exceed the permissible level, selected according to the feeder reliability criteria.

For research on the parameters of the feeder operation with a vibro-impact adaptive drive, a mathematical model of a feeder with a vibration oscillations generator of limitedpower and a calculation algorithm for its numerical studies, which are implemented in a computer program [10], have been developed. In accordance with the declared requirements to the feeder oscillations modes, the research of the settings of their parameters was performed. These researches were carried out at the basic parameters of the 
feeder, given in Table 1.

Table 1. Basic parameters of a vibrating feeder for research.

\begin{tabular}{|c|c|c|}
\hline Parameter & Symbol & Value \\
\hline Mass of feeder tray, $\mathrm{kg}$ & $m_{1}$ & 300 \\
\hline Mass of impactor, $\mathrm{kg}$ & $m_{2}$ & 160 \\
\hline $\begin{array}{l}\text { Stiffness of two-side elastic bonds between } m_{1} \text { and the } \\
\text { stationary base, } \mathrm{N} / \mathrm{m}\end{array}$ & $c_{p 10}$ & 1680000 \\
\hline Viscosity coefficient of elastic bonds $c_{p 10}$ & $b_{p 10}$ & 2000 \\
\hline $\begin{array}{l}\text { Stiffness of two-side elastic bonds between } m_{1} \text { and } \\
\qquad m_{2}, \mathrm{~N} / \mathrm{m}\end{array}$ & $c_{p 21}$ & 278260 \\
\hline Viscosity coefficient of elastic bonds $c_{p 21}$ & $b_{p 21}$ & 2000 \\
\hline Stiffness of the upper constraints, $\mathrm{kN} / \mathrm{m}$ & $c_{r 12}$ & 20000 \\
\hline Viscosity coefficient of elastic bonds $c_{r 12}$ & $b_{r 12}$ & 2000 \\
\hline Static gap $c_{r 12}, \mathrm{~m}$ & $\delta_{12}$ & $0-0.008$ \\
\hline Stiffness of the lower constraints, $\mathrm{kN} / \mathrm{m}$ & $c_{r 21}$ & 20000 \\
\hline Viscosity coefficient of elastic bonds $c_{r 21}$ & $b_{r 21}$ & 2000 \\
\hline Static gap $c_{r 21}, \mathrm{~m}$ & $\delta_{21}$ & $0-0.008$ \\
\hline $\begin{array}{c}\text { Type of vibrating oscillator - electromechanical } \\
\text { vibrator }\end{array}$ & EB100L6U3 & - \\
\hline $\begin{array}{l}\text { Synchronous angular speed of vibrator axle rotation, } \\
\mathrm{rad} / \mathrm{s}\end{array}$ & $\omega_{y}$ & 104.67 \\
\hline Nominal angular speed of vibrator axle rotation, $\mathrm{rad} / \mathrm{s}$ & $\omega_{v}$ & 97.34 \\
\hline Weight of debalances on vibrator axle, $\mathrm{kg}$ & $m_{0}$ & 12.28 \\
\hline Eccentricity of debalances, $\mathrm{m}$ & $r$ & $0-0.061$ \\
\hline $\begin{array}{c}\text { Force of excitation of forced oscillations at } \\
\text { synchronous frequency, } \mathrm{kN}\end{array}$ & $m_{0} r \omega_{c}^{2}$ & $0-8.2$ \\
\hline Static moment, $\mathrm{kg} \cdot \mathrm{m}$ & $m_{0} r$ & $0-0.75$ \\
\hline Nominal power of an asynchronous electric motor, $\mathrm{kW}$ & $N_{n}$ & 2.4 \\
\hline Number of pairs of electric motor poles, pairs & $p$ & 3 \\
\hline Coefficient of engine capacity to overload & $\zeta$ & 2.4 \\
\hline Frequency of current in the network, $\mathrm{Hz}$ & $f_{c}$ & 50 \\
\hline
\end{tabular}

The parameters of the settings that can change the oscillations of the feeder with the vibro-impact adaptive drive include the gaps $\delta_{12}$ and $\delta_{21}$ to one-side elastic elements that limit the movement of the impactor of the vibro-impact drive and the eccentricity of the vibrator debalanses $r$, the regulation of which changes the excitation of the excitatory force.

\section{Research results and discussion}

Figure 1 shows the dependences of accelerations of the feeder masses $m_{1}$ and $m_{2}$ with the growth of the gaps $\delta_{12}$ and $\delta_{21}$ in the range $0-12 \mathrm{~mm}$ in a $1 \mathrm{~mm}$ step, calculated by the mathematical model of the feeder by the method of continuation by parameter.

It should be noted that in calculations in a mathematical model of a feeder, two methods of research can be used: continuation by parameter and method of discrete selection of this 
parameter.

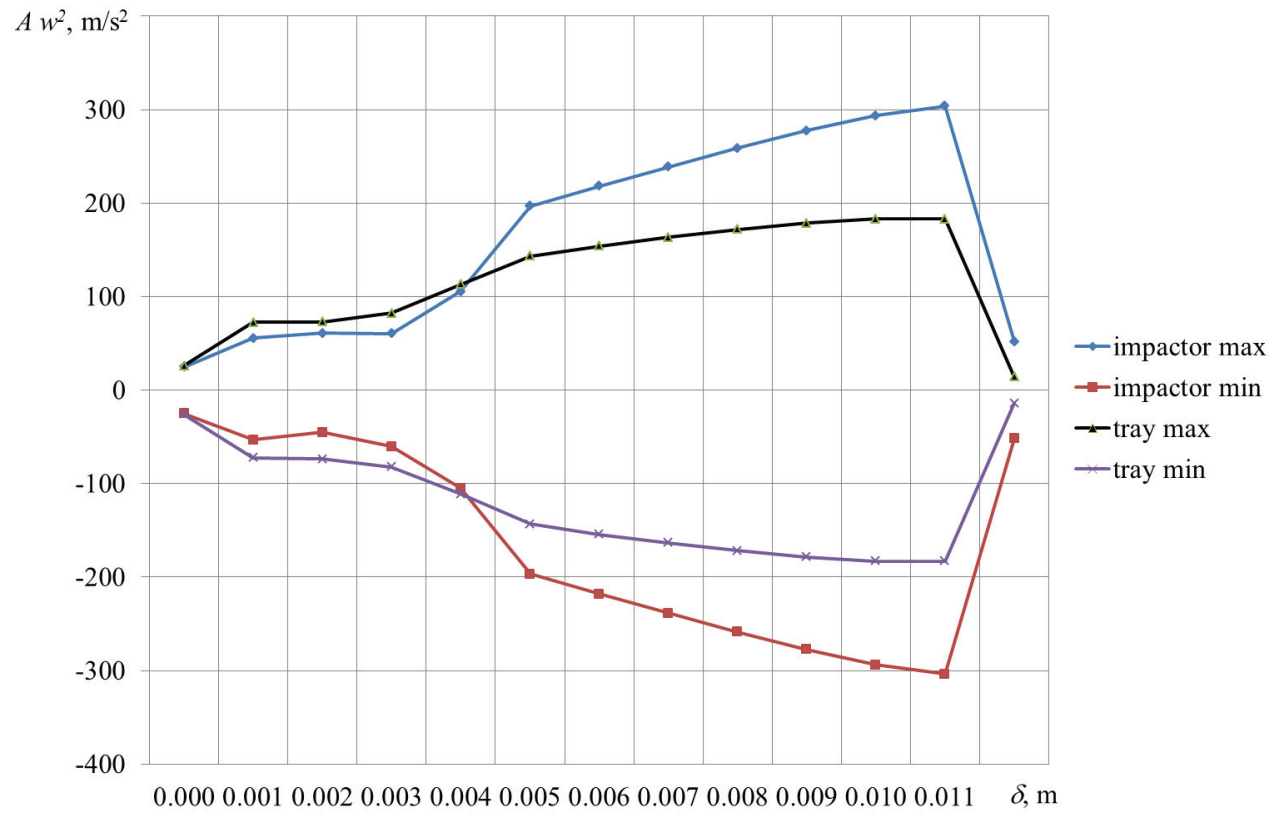

Fig. 1. Dependences of the feeder masses accelerations, obtained by the method of continuation by parameter with increasing gaps between the impactor and one-side elastic elements.

These methods allow taking into account the influence of the initial conditions on the solution of the mathematical model equations to the feeder oscillations. In the method of continuation by parameter, as the initial approximation of the solution of the equations in the next step of the research, decisions made in the previous step are selected. The method of discrete selection differs from the method of continuation of the parameter by the fact that when changing the research step of the parameter, the initial conditions do not change and remain the same as in the first step of the research.

The analysis of dependencies (Fig. 1) shows that when the system starts with a parameter continuation method, provided that at the initial moment of time $t=0$, the system is at rest, the vibro-impact modes of the feeder drive oscillations are excited in the range of changes in the gaps of $0-11 \mathrm{~mm}$. In the range of 11 to $12 \mathrm{~mm}$, the vibration oscillation breakdown occurs and the system moves to vibrations without interaction with one-side elastic elements, with the accelerations of the impactor and the tray, respectively, equal to 52 and $14 \mathrm{~m} / \mathrm{s}^{2}$. At the same time, the growth of gaps in the range of $0-11 \mathrm{~mm}$ ambiguously affects the acceleration of the feeder mass. The acceleration of the tray $m_{1}$ grows throughout the range of vibro-impact oscillations excitation, whereas as acceleration of the impactor $m_{2}$, at the beginning of the range, when the gaps vary from 1 to $3 \mathrm{~mm}$, they decrease and then begin to increase with greater intensity than the tray accelerations, reaching maximum at intervals at $11 \mathrm{~mm}$, for the impactor of $304 \mathrm{~m} / \mathrm{s}^{2}$, and for the tray of $183 \mathrm{~m} / \mathrm{s}^{2}$.

When the system is started by method of discrete selection of parameters (intervals) in the range of $0-10 \mathrm{~mm}$ (Fig. 2) with zero initial conditions at each step of the research, vibro-impact modes of the system oscillations are excited in the range of growth of gaps of 1-8 mm, with maximum accelerations at gaps of $8 \mathrm{~mm}$, equal, for the impactor $259 \mathrm{~m} / \mathrm{s}^{2}$ and for the tray $172 \mathrm{~m} / \mathrm{s}^{2}$.

Unlike the previous research method (Fig. 1), the breakdown of vibration oscillation regime of the system occurs earlier, in the range of the growth of the gaps of 8 to $9 \mathrm{~mm}$, 
and then non-impact oscillations are further excited, with the same accelerations of the impactor of $52 \mathrm{~m} / \mathrm{s}^{2}$ and the tray of $14 \mathrm{~m} / \mathrm{s}^{2}$, as in Figure 1 .

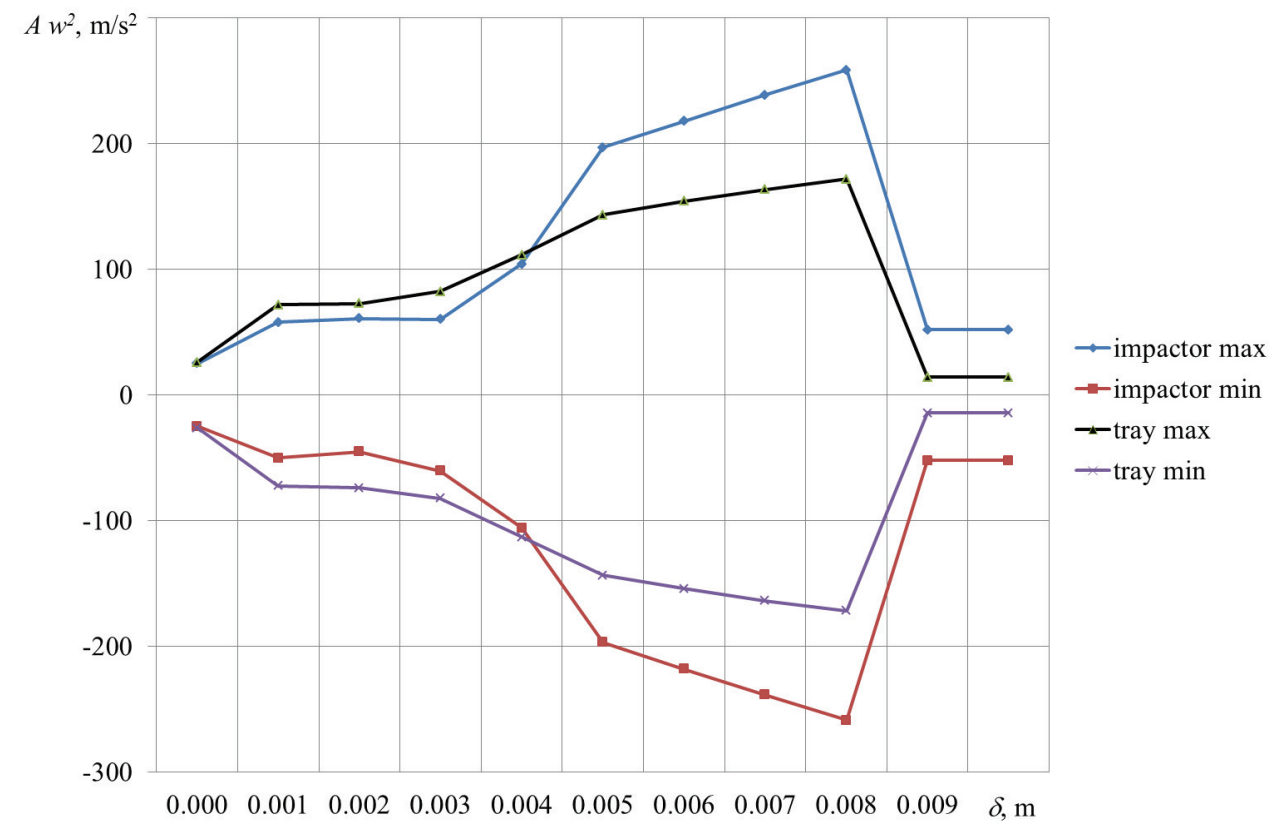

Fig. 2. Dependences of the feeder masses accelerations, obtained by the method of discrete selection of the parameter at the growth of the gaps between the impactor and one-side elastic elements.

A more detailed study of the system oscillations by the continuation method by the parameter in the range of changes in the gaps of 5 to $14 \mathrm{~mm}$ in increments of $0.5 \mathrm{~mm}$, with a direct and reverse change of this parameter in the calculations (Fig. 3), show that the breakdown of vibro-impact oscillations is in the range of change of the gaps of 11.5 to $12 \mathrm{~mm}$, and their creation, when reversely calculated with the change of the gaps of 14 to $5 \mathrm{~mm}$, in the range of 6 to $5.5 \mathrm{~mm}$.

Note that in the parameters field of oscillations with gaps of 5.5 to $11.5 \mathrm{~mm}$, if for some reason vibro-impact oscillations disappear, and the system will switch to the regime of nonimpact oscillations of the masses, vibro-impact modes can be recreated only with reduced gaps up to $5.5 \mathrm{~mm}$. The field of vibro-impact oscillation parameters in the range of gaps of 8 to $11.5 \mathrm{~mm}$ is unstable, and such that oscillations are excited only with a gradual change with small increments.

The results of studies the influence of the gaps on the oscillations of the feeder model indicate that when the system starts from rest, vibro-impact oscillations of the system will be excited in the range of gaps changes of 0 to $8 \mathrm{~mm}$. For larger than $8 \mathrm{~mm}$ gaps, nonimpact oscillation modes will be excited in the system. However, when the system exits on the stationary modes of oscillation, in the range of 0 to $8 \mathrm{~mm}$ gaps changes, then with a small step to start increasing them, the vibro-impact oscillations modes will be excited with an increase in the gaps up to $11.5 \mathrm{~mm}$. With further increase in the gaps, a breakdown of vibro-impact oscillations and the transition of the system to non-impact mode oscillations will occur.

Researches of phase diagrams and oscillations spectra of a feeder masses show that quasiperiodic oscillations are excited in the range of changes in the gaps of 5.5 to $8 \mathrm{~mm}$, as evidenced by the sections of the Poincare phase diagrams for the 9800 periods of stationary oscillations of the feeder impactor (Fig. 4) and spectrograms of accelerations oscillations of the feeder masses (Fig. 5). 


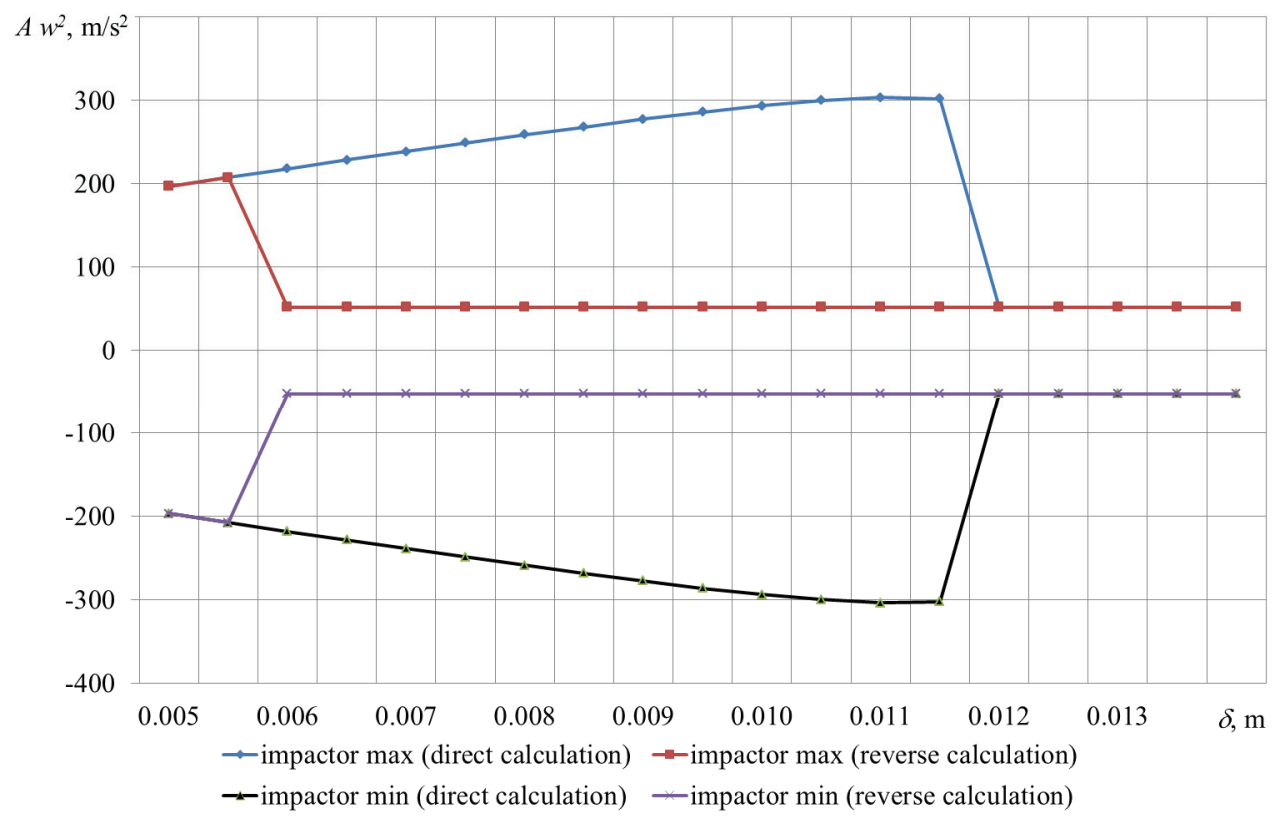

Fig. 3. Dependences of the feeder impactor accelerations, obtained by the method of continuation by parameter with the growth of the gaps between the impactor and one-side elastic elements.

The study of the vibrations spectrum shows that oscillations in the feeder system excite both superharmonic and subharmonic oscillations with frequencies that are lower than the frequency of forced oscillations. That is, the low-frequency oscillations are excited in the feeder oscillating system. As already noted, polyfrequency oscillations promote to the dissemination of vibrations into the depths of an massive of bulk media, including by excitement of low-frequency component oscillations. The energies dissipation of lowfrequency oscillations in a massive of bulk media is slower than that of high-frequency, which is related with a larger wavelength of their dissemination. That is, when the broad spectrum of frequencies excited in a bulk medium, the loss of energy of the low-frequency component oscillations will be less than high-frequency, and they will spread in the massive of bulk media at a greater distance than high-frequency ones. Therefore, it is important to excite the low-frequency components of these oscillations in the polyfrequency spectrum of oscillations, which are directed to the bulk media massive.

Analysis of dependencies on Figure 1 shows that with oscillations of the feeder with the basic parameters (Table 1), in the range of changes in gaps of 4 to $5 \mathrm{~mm}$, the acceleration of the impactor becomes larger than the acceleration of the tray, which is not acceptable in the long-term operation of the electromechanical vibrator, due to the growth of dynamic loads on vibration drive. Therefore, when choosing the operating modes of feeders with drives from electromechanical vibrators, it is acceptable to set gaps in the range of 1-4 mm, with impactor accelerations, which does not exceed the level of $100 \mathrm{~m} / \mathrm{s}^{2}$, which promotes the prolongation of the resource of their exploitation. At gaps of $3 \mathrm{~mm}$ and increasing the load on the feeder tray due to an increase in the mass of reflacted ore attached to it in the amount of $2700 \mathrm{~kg}$, acceleration of the vibration drive impactor will increase up to 2.38 times, of 60 to $143 \mathrm{~m} / \mathrm{s}^{2}$, which positively affects on the continuation of the vibration output of bulk media [1] and, in the short term, does not significantly impair the vibrator performance.

For heavy vibrating feeders used to vibration output and load reflacted ores from chambers of wining blocks with drive by asynchronous motors, fixed on a stationary frame, heavy-duty bearings are usually installed on debalanced vibrators. 


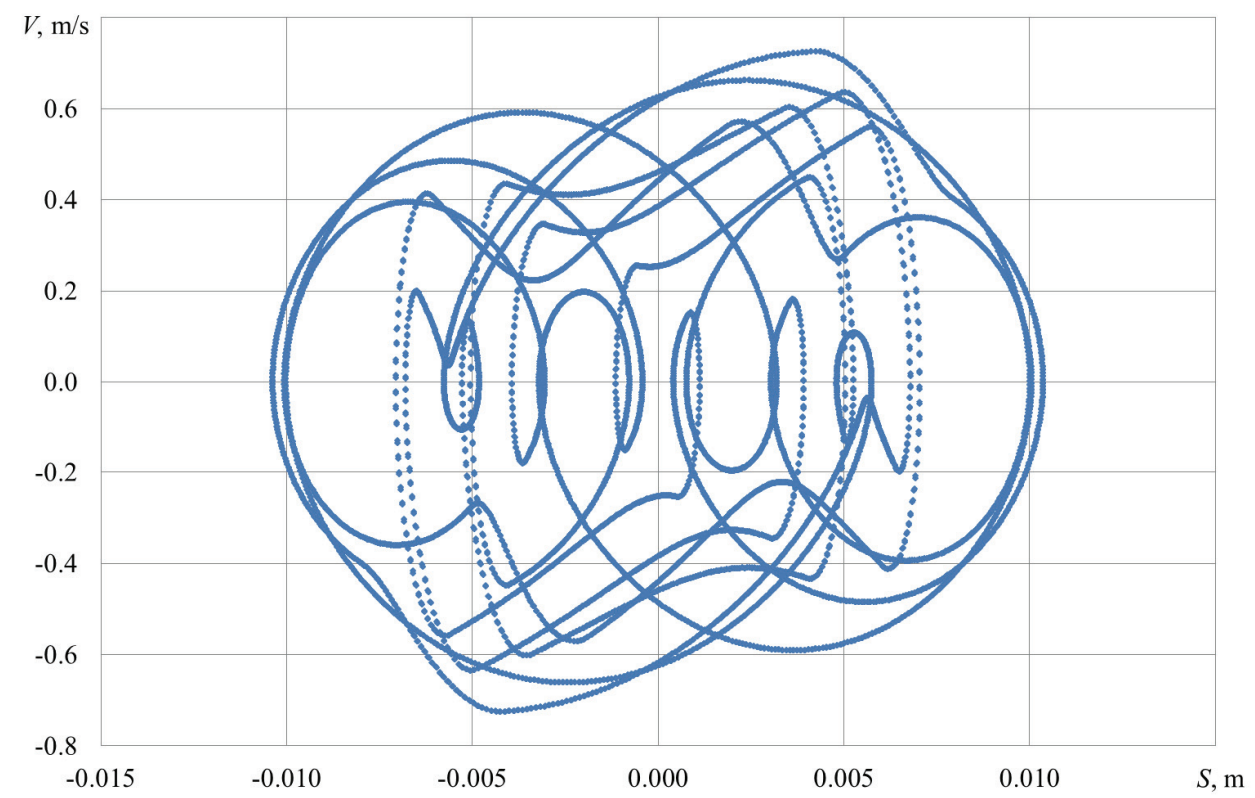

Fig. 4. The sections of the Poincaré phase diagrams for the 9800 periods of stationary oscillations of the feeder impactor with gaps of $6 \mathrm{~mm}$.

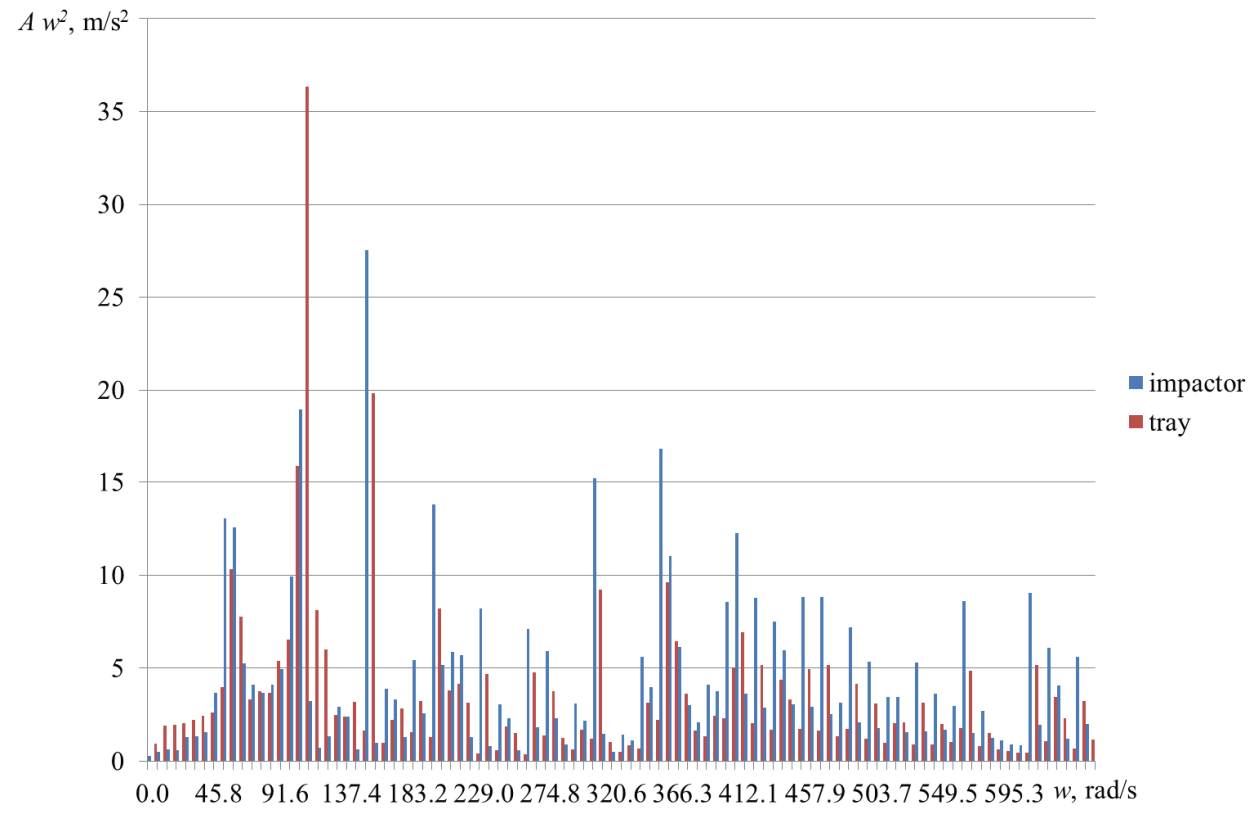

Fig. 5. Spectrograph of a feeder masses stationary oscillations accelerations with gaps of $6 \mathrm{~mm}$.

Therefore, acceleration of the impactor of their vibro-impact drive in normal vibration output regimes, it is possible to provide up to $200 \mathrm{~m} / \mathrm{s}^{2}$. In modes of blockage, in the short term, the acceleration of the impactor, depending on the setting, can increase to 400 $500 \mathrm{~m} / \mathrm{s}^{2}$. Given the possibility of achieving such a level of acceleration and growth, with this, the spectral density and width of the frequency spectrum of oscillations excited in the feeder vibrational system, as compared with typical feeders, will increase the productivity 
and efficiency of the reflacted ore vibration output.

The parameters of the setting by which it is possible to change the modes of vibration of the feeder with a vibro-impact adaptive drive (Table 1), also refers to the eccentricity of the debalances of the oscillation vibration generator $r$, the regulation of which changes the vibrator excitatory force. The eccentricity of the debalances of the electromechanical vibrator, set on the feeder, varies in the range of 0-61 $\mathrm{mm}$. In this case, the force excited by the oscillator vibrator at the synchronous frequency of excitation varies from 0 to $8.2 \mathrm{kN}$.

Researches of the influence of eccentricity (excitatory force) on the feeder oscillations (Fig. 6) with the discrete change of this parameter in the range of 1-61 $\mathrm{mm}$ in a step of $6 \mathrm{~mm}$ shows that the acceleration of the impactor and the tray increases with $r$ ranging from $1 \mathrm{~mm}$ to $43 \mathrm{~mm}$. In the range of $43-55 \mathrm{~mm}$, the acceleration decreases and further, of 55 to $61 \mathrm{~mm}$, slightly increase. The most favorable range for the oscillator vibrator load is the range of eccentricity ranging of 43 to $61 \mathrm{~mm}$, which is desirable to choose when adjusting the feeder oscillation with the electromechanical type of vibrator.

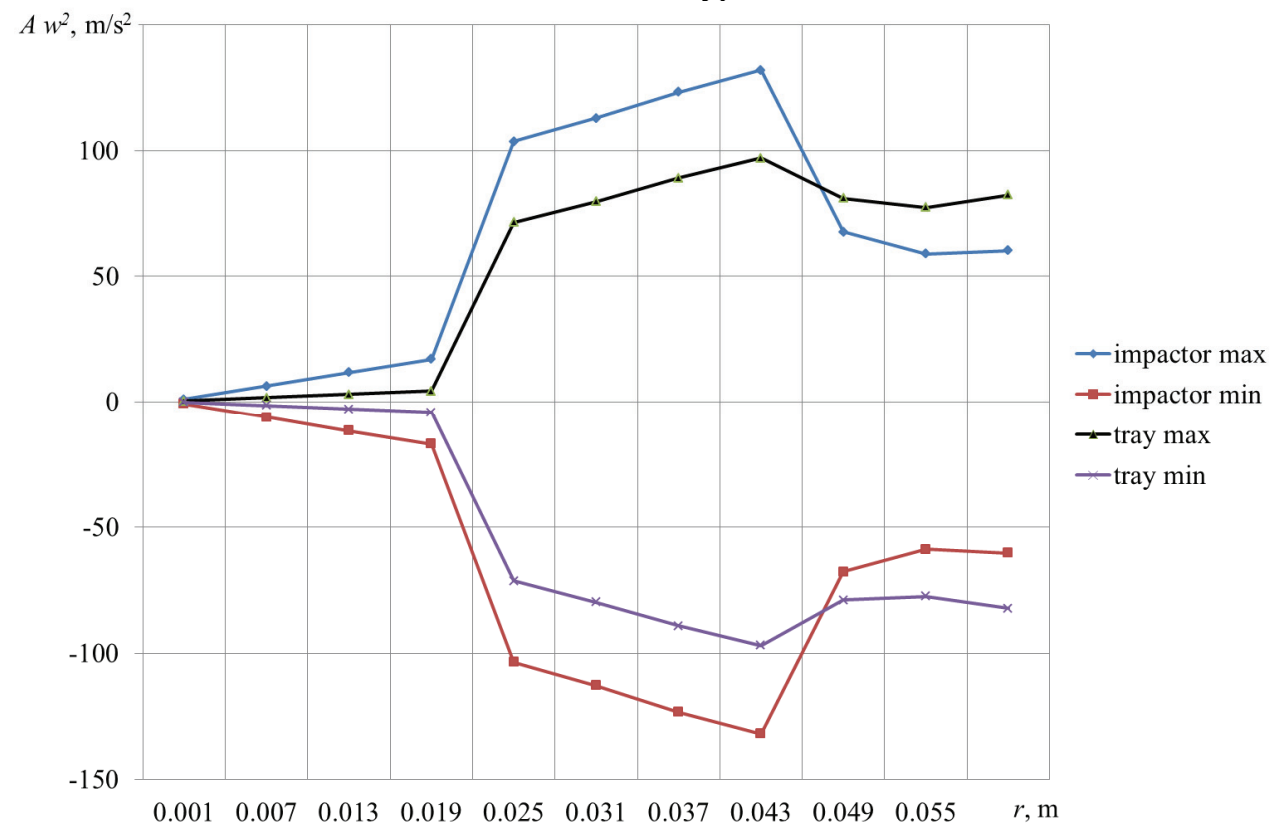

Fig. 6. Dependence of accelerations of a feeder masses at the method of discrete growth of the debalanced vibrator eccentricity.

Dependences of the changes in the reactions of one-sided elastic bonds (Fig. 7) show that vibro-impact oscillations in the system begin to be excited with an eccentricity growth from 19 to $25 \mathrm{~mm}$. That is, when the excitation force is less than $3.36 \mathrm{kN}$, the vibro-impact oscillations in the system are not excited.

Researches of the effect of changes in the eccentricity of debalance on the oscillations of the feeder's impactor by the method of continuation by the parameter with the direct and reverse change of this parameter in calculations in the same range and with the same step as in the discrete method of research, show (Fig. 8) that the vibro-impact oscillations in the system begins to excite with eccentricity growth of 25 to $31 \mathrm{~mm}$. In the range of $43-55 \mathrm{~mm}$, the acceleration decreases and further, of 55 to $61 \mathrm{~mm}$, slightly increase. When reverse calculation, the vibro-impact oscillation breakdown occurs when the eccentricity decreases of $13 \mathrm{~mm}$. It should be noted that vibro-impact oscillations with an eccentricity of $31 \mathrm{~mm}$ are unstable, and can not be recreated without the system returning to its parameters with an eccentricity of $31 \mathrm{~mm}$. 


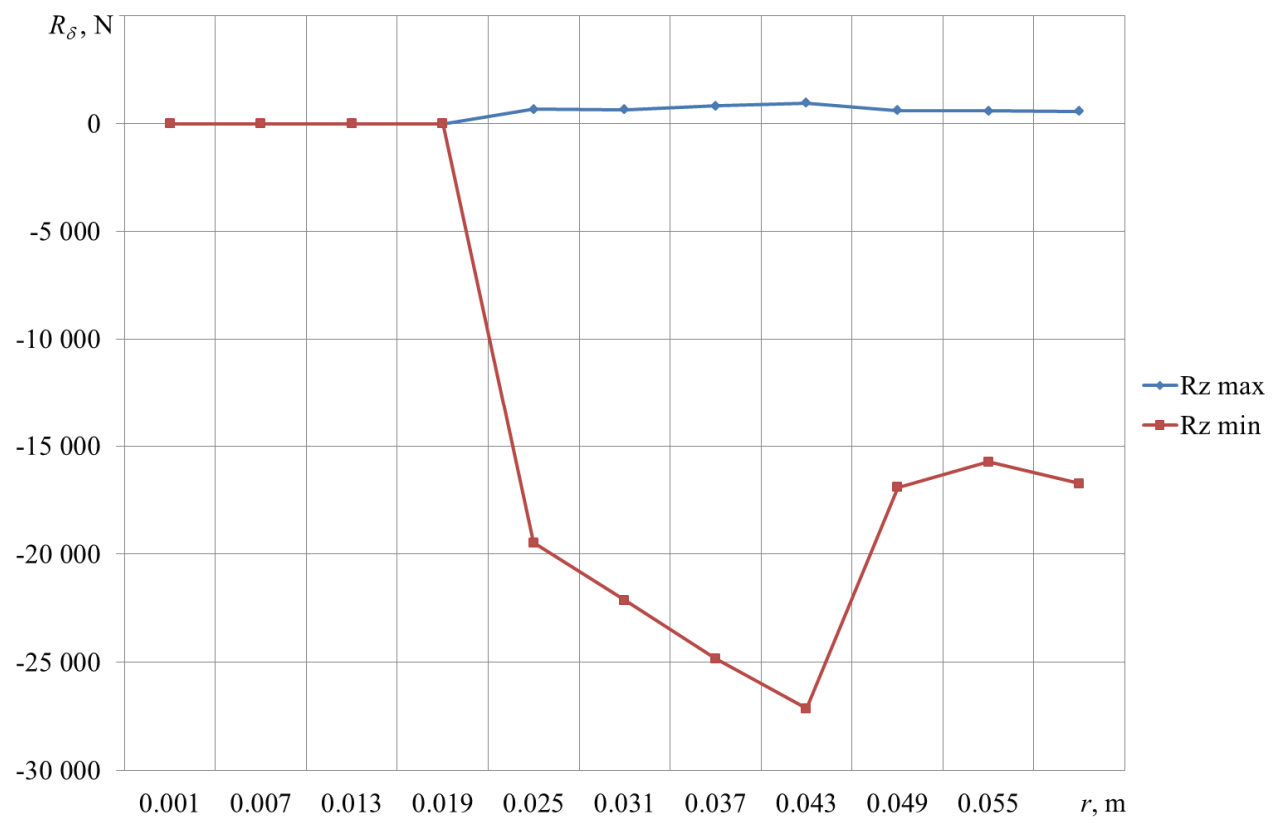

Fig. 7. Dependence of changes in the reactions of one-sided elastic bonds at the method of discrete growth of the debalanced vibrator eccentricity.

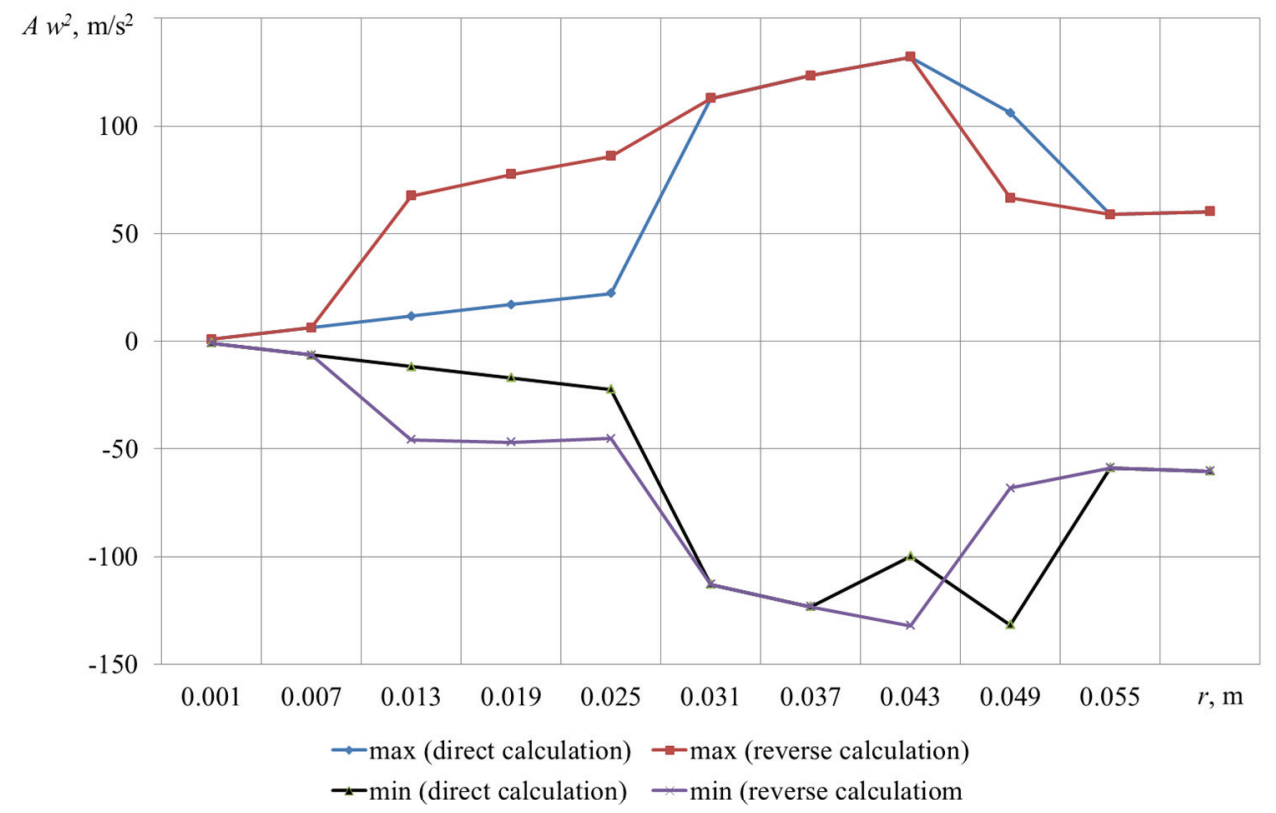

Fig. 8. Dependence of the feeder masses accelerations with increasing the debalanced vibrator eccentricity by the method of continuation by parameter.

\section{Conclusions}

Research results of oscillations of a model of a vibrating feeder with vibro-impact adaptive 
drive at basic parameters, as in Table 1, show that the modes of the feeder vibrations depend on the method of research, or the initial conditions for the solution of the mathematical model equations. Depending on this, the fields of the existence of vibroimpact modes of the feeder masses oscillations varies. At the research method of continuation by the parameter, there are fields of unstable vibro-impact oscillations that do not arise in the discrete method of research. Since in the physical model of the vibration feeder with parameters, as in Table. 1, during oscillations, gradual adjustment of the settings of its operation modes (the gaps and eccentricity, or the excitatory force of the vibrators) is not foreseen, then the output of the feeder on the mode of oscillation, provided only by the discrete method of research, is possible. In view of this, the most favorable conditions for the effective vibration of the reflacted ore from the wining blocks chambers, arise when the gaps change to one-sided elastic elements in the range of 1 to $4 \mathrm{~mm}$, the eccentricity of 43 to $61 \mathrm{~mm}$. In this case, the force excited by the oscillator vibrator at the synchronous frequency varies in the range of 5.8 to $8.2 \mathrm{kN}$. With such settings, oscillating system of the feeder excite vibro-impact oscillations with accelerations of the impactor and vibrator, which are smaller than the tray speed, and which are rational to ensure its reliable operation with effective vibration output. With increasing load on the feeder tray from the pillar of reflacted ore in the chamber, the acceleratioms of the feeder impactor increases, but in the short term they can reach hundreds of $\mathrm{m} / \mathrm{s}^{2}$, which is positive for the vibration continuation. It should be noted that due to gaps in one-sided elastic elements, the excitation of the feeder tray will be carried out under any load, even under blockage.

On heavy vibrating feeders that are used to vibrate and load reflacted ores from wining blocks chambers driven by asynchronous motors, fixed on a stationary frame, bearings of heavy series are installed on debalanced vibrators.

Therefore, acceleration of the impactor of their vibro-impact drive in normal vibration output modes, it is possible to provide at a level of $200 \mathrm{~m} / \mathrm{s}^{2}$. Under conditions of blockage, in the short term, the accelerator of a impactor can increase to $400-500 \mathrm{~m} / \mathrm{s}^{2}$, depending on the setting. Given the possibility of achieving such a level of acceleration and growth, in this case, the spectral density and the width of the frequency spectrum of oscillations that is excited in the vibrational system of the feeder, this will ensure high productivity and efficiency of the vibration output of the reflacted ore from the wining blocks chambers.

\section{References}

1. Shevchenko, V.G., Shevchenko, G.A., Lebed, G.B. (2016). Recommended practice for using resource-saving technologies and tools for fine classification of uranium ores by size and refuse dehydration. Mining of mineral deposits, 10 (1), 69-76

2. Bulat, A.F., Shevchenko, G.A. (2010). Vliyanie polichastotnyih kolebaniy proseivayuschih poverhnostey vibratsionnyih grohotov na razdelenie syipuchih materialov. Scientific bulletin of the National mining university, 4, 92-97

3. Shevchenko, G.A., Shevchenko, V.G., Bobyl'ev, A.A., Ishchuk, M.A. (2013). Polichastotnyie kolebaniya proseivayuschih poverhnostey vibratsionnyih grohotov dlya razdeleniya syipuchih sred. Nauchno-tehnicheskoe obespechenie gornogo proizvodstva: Trudyi Instituta gornogo dela im. D.A. Kunaeva, 84, 39-44

4. Shevchenko, G.A., Shevchenko, V.G., Shlyakhova, M.A., Lebed, G.B. (2015). Rezonansyi vibroudarnyih system. Geo-technical mechanics, 121, 28-38

5. Poturaev, V.N., Dyirda, V.I, Avdeev, O.K., Nadutyiy, V.P., Poddubnyiy, I.K., Finogeev, V.I. (1981). Vibratsionnyie mashinyi dlya vyipuska i dostavki rudyi. Kyiv: Naukova dumka

6. Poturaev, V.N., Dyirda, V.I., Avdeev, O.K., Poddubnyiy, I.K., Gordienko, N.A., Koval, A.V., Lisitsa, N.I., Finogeev, V.I. (1989). Vibrodostavochnyie kompleksyi V 
tehnologiyah razrabotki rudnyih mestorozhdeniy. Kyiv: Naukova dumka

7. Kyrychenko, E., Samusya, V., Kyrychenko, V., Antonenko, A. (2015). Thermodynamics of multiphase flows in relation to the calculation of deep-water hydraulic hoisting. New Developments in Mining Engineering 2015: Theoretical and Practical Solutions of Mineral Resources Mining, 305-312

8. Bondarenko, V.I., Samusya, V.I., Smolanov, S.N. (2005). Mobile lifting units for wrecking works in pit shafts. Gornyi Zhurnal, 5, 99-100

9. Pivnyak, G., Samusia, V., Oksen, Y., Radiuk, M. (2014). Parameters optimization of heat pump units in mining enterprises. Progressive technologies of coal, coalbed methane and ores mining, 19-24

10. Shevchenko, G.A., Shevchenko, V.G. (2015). Model vibratsionnogo polichastotnogo grohota s ogranichennyim istochnikom vozbuzhdeniya. Vibration in engineering and technology, 4 (80), 105-113 